\title{
Metabolic predictors of ischemic heart disease and cerebrovascular attack in elderly diabetic individuals: difference in risk by age
}

Toshio Hayashi ${ }^{*}$, Atsushi Araki ${ }^{2}$, Seinosuke Kawashima ${ }^{3}$, Hirohito Sone ${ }^{4}$, Hiroshi Watanabe ${ }^{5}$, Takashi Ohrui ${ }^{6}$, Koutaro Yokote ${ }^{7}$, Minoru Takemoto ${ }^{7}$, Kiyoshi Kubota ${ }^{8}$, Mitsuhiko Noda ${ }^{9}$, Hiroshi Noto ${ }^{9}$, Koichiro Ina ${ }^{7}$, Hideki Nomura ${ }^{1,10}$ and on behalf of Japan CDM group

\begin{abstract}
Background: High LDL-cholesterol (LDL-C) and glucose levels are risk factors for ischemic heart disease (IHD) in middle-aged diabetic individuals; however, the risk among the elderly, especially the very elderly, is not well known. The aim of this study was to identify factors that predict IHD and cerebrovascular attack (CVA) in the elderly and to investigate their differences by age.

Methods: We performed a prospective cohort study (Japan Cholesterol and Diabetes Mellitus Study) with 5.5 years of follow-up. A total of 4,014 patients with type 2 diabetes and without previous IHD or CVA (1,936 women; age $67.4 \pm 9.5$ years, median 70 years; $<65$ years old, $n=1,261 ; 65$ to 74 years old, $n=1,731$; and $\geq 75$ years old, $n=1,016$ ) were recruited on a consecutive outpatient basis from 40 hospitals throughout Japan. Lipids, glucose, and other factors related to IHD or CVA risk, such as blood pressure (BP), were investigated using the multivariate Cox hazard model.

Results: One hundred fifty-three cases of IHD and 104 CVAs (7.8 and 5.7/1,000 people per year, respectively) occurred over 5.5 years. Lower HDL-cholesterol (HDL-C) and female gender were correlated with IHD in patients $\geq 75$ years old (hazard ratio (HR):0.629, $\mathrm{P}<0.01$ and 1.132, $\mathrm{P}<0.05$, respectively). In contrast, systolic BP (SBP), HbA1C, LDL-C and non-HDL-C were correlated with IHD in subjects $<65$ years old $(P<0.05)$, and the LDL-C/HDL-C ratio was correlated with IHD in all subjects. HDL-C was correlated with CVA in patients $\geq 75$ years old (HR: $0.536, \mathrm{P}<0.01$ ). Kaplan-Meier estimator curves showed that IHD occurred more frequently in patients $<65$ years old in the highest quartile of the LDL-C/HDL-C ratio. In patients $\geq 75$ years old, IHD and CVA were both the most frequent among those with the lowest HDL-C levels.

Conclusions: IHD and CVA in late elderly diabetic patients were predicted by HDL-C. LDL-C, HbA1C, SBP and non-HDL-C are risk factors for $\mathrm{HD}$ in the non-elderly. The LDL-C/HDL-C ratio may represent the effects of both LDL-C and HDL-C. These age-dependent differences in risk are important for developing individualized strategies to prevent atherosclerotic disease.
\end{abstract}

Trial registration: UMIN-CTR, UMIN00000516

Keywords: Elderly, Diabetes mellitus, Cardiovascular diseases, HDL-C, LDL-C/HDL-C ratio

\footnotetext{
* Correspondence: hayashi@med.nagoya-u.ac.jp

'Department of Geriatrics, Nagoya University Graduate School of Medicine,

65 Tsuruma-cho, Showa-ku, Nagoya, Japan

Full list of author information is available at the end of the article
} 


\section{Introduction}

Type 2 diabetes mellitus, dyslipidemia and aging are independent risk factors for cardiovascular diseases, such as ischemic heart disease (IHD). Within diabetic individuals, lipids, especially LDL-cholesterol (LDL-C), blood pressure (BP), and diabetic control are risk factors for IHD [1-4]. For example, the United Kingdom Prospective Diabetes Study (UKPDS) showed the importance of BP, lipids, and diabetic control in the prevention of IHD in newly diagnosed diabetic individuals(mean age 53 years, range 25-65 years), and subsequent studies have confirmed these findings $[1,2]$. However, the risk factors for IHD or cerebrovascular attack (CVA) in elderly diabetic individuals (older than 65 years), particularly in late elderly diabetic individuals (older than 75 years), have not been identified.

In Western countries, the evidence suggests that middle-aged diabetic individuals have an IHD risk similar to that of non-diabetic patients who have experienced a myocardial infarction, and the guidelines for diabetes treatment recommend that the LDL-C level should be less than $100 \mathrm{mg} / \mathrm{dl}$, which is similar to the recommendation for the secondary prevention of myocardial infarction $[5,6]$. However, it is unknown whether the same risk exists for elderly diabetic individuals. Additionally, many guidelines recommend strict control of LDL-C levels to prevent atherothrombotic diseases, especially in diabetic patients, yet recommend the same HDL-cholesterol (HDL-C; $40 \mathrm{mg} / \mathrm{dl}$ ) and triglyceride (TG; $150 \mathrm{mg} / \mathrm{dl}$ ) levels as for non-diabetic individuals [5-7]. There are few reports on the absolute risk conferred by HDL-C and TG in elderly diabetic patients.

Additionally, diabetes can either develop in the elderly or continue through old age after an earlier onset. Even in elderly individuals without diabetes, postprandial hyperglycemia occurs because of a delay in insulin secretion in response to feeding and may contribute to an increase in the number of elderly diabetic patients [8]. The International Diabetes Federation (IDF) reports that the number of diabetic patients increased from 30 million in 1987 to 246 million in 2007 (7\% of adults) and speculates that it will increase to 380 million by 2027 [9]. In Japan, 30\% of diabetic individuals were elderly in 1997 (13\% of the elderly suffered from diabetes mellitus), which increased to $40 \%$ in 2007 (17\% of the elderly). Furthermore, individuals older than 75 (13 million) comprise over $10 \%$ of the total population. However, no large-scale investigations have focused on type 2 diabetes mellitus in the elderly, especially in the late elderly, or those older than 75 [10]. Thus, evaluating the metabolic predictors of atherosclerotic diseases, such as IHD and CVA, in elderly diabetic individuals is important. For these reasons, we organized the Japan Cholesterol and Diabetes Mellitus Study (JCDM) to evaluate which factors can predict IHD or CVA in diabetic patients, including the elderly. Our elderly sample population included 1,016 late elderly, who were older than 75 and performed independent daily life activities at outpatient clinics [11].

\section{Materials and methods Subjects}

The JCDM is a prospective, cohort study that consists of 4,014 Japanese diabetic individuals from 40 hospitals throughout Japan who were recruited on a consecutive outpatient basis between September 2004 and March 2005 (1,936 women; mean age $67.4 \pm 9.5$ years, median age 70 years; Figure 1) [11]. The JCDM protocol, which is in accordance with the provisions of the Declaration of Helsinki, received ethical approval from the institutional review boards of all the participating institutes. Written informed consent was obtained from all patients. The criteria from the American Diabetes Association for type 2 diabetes mellitus diagnosis were used [6]. Patients with previous IHD (myocardial infarction, unstable angina pectoris, angioplasty, or bypass grafting) or CVA (recent stroke with admission within the past 24 months) were excluded, as were patients whose medical records concerning plasma lipids (TG, HDL-C and total cholesterol or LDL-C) were not provided. The other exclusion criteria were a history or complication of serious heart disease (e.g., severe arrhythmia, heart failure, cardiomyopathy, valvular disease, or congenital disease), serious hepatic or renal disease with admission within the past 24 months, malignant disease, intention to undergo surgery, any illness with a poor prognosis of less than one year, and judgment by the physician in charge that the patient was not suitable for the study.

At 24 months (2007), 92.3\% of the enrolled patients were followed up, and $84.1 \%$ were followed up at 66 months (2010). Patients were divided into groups based on age at registration: younger than 65 (nonelderly, $\mathrm{n}=1,267$ ), 65 to 74 years old (early elderly, $\mathrm{n}=1,731$ ) and older than 75 (late elderly, $\mathrm{n}=1,016$ ). These age categories are used frequently in Japan for the study of elderly patients and for health care insurance purposes [12].

\section{Outcome measurements}

The primary endpoints were the incidence of IHD and CVA, specifically fatal and non-fatal myocardial infarction and other non-fatal events, including unstable angina pectoris, angioplasty, stenting, coronary artery bypass grafting and stroke. Detailed definitions of each event are shown below. Transient ischemic attacks were included only if definite focal lesions from the attack were confirmed by head CT or MRI. 


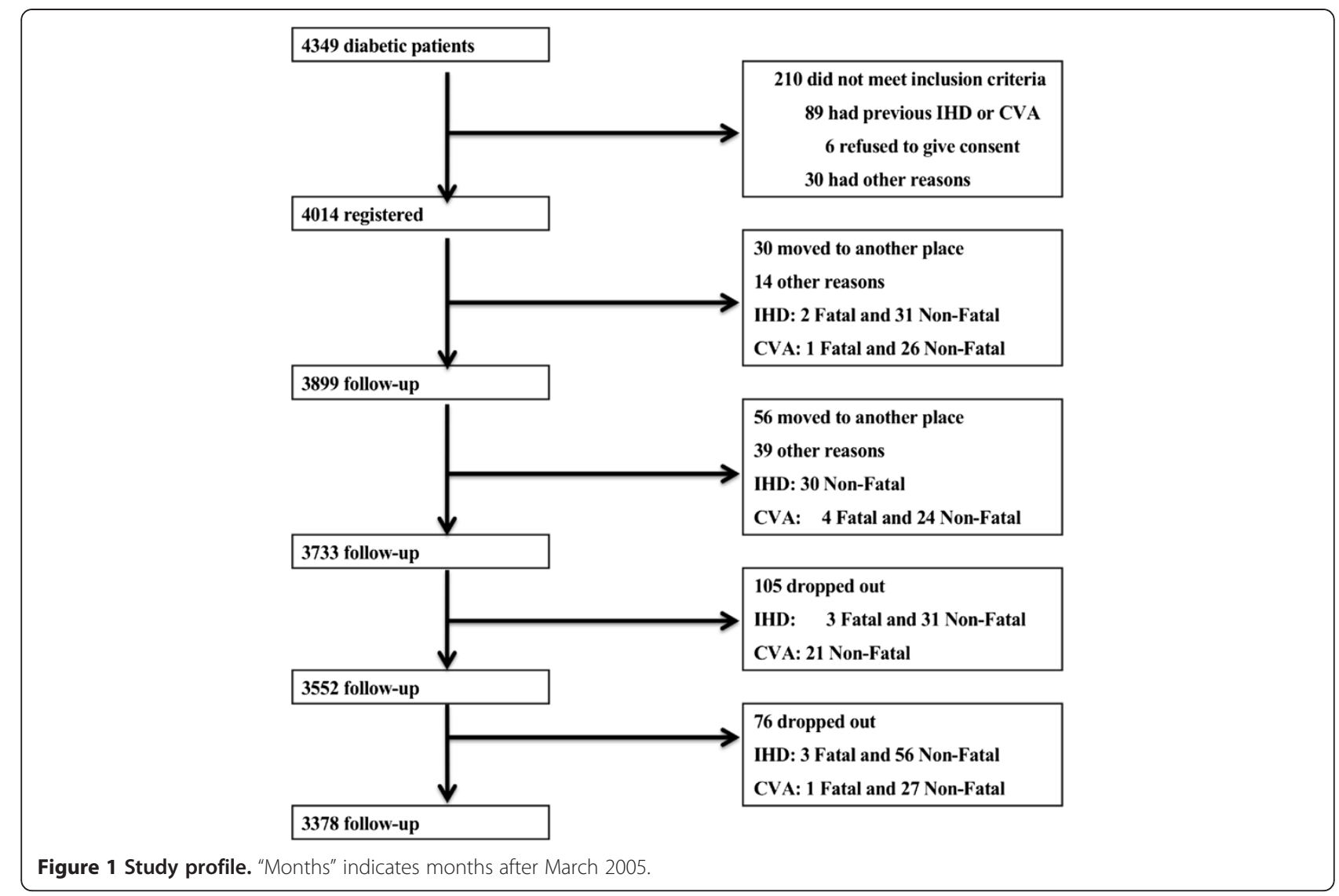

\section{Risk factor assessment}

Metabolic factors, such as the levels of plasma lipids, fasting plasma glucose (FPG), and $\mathrm{HbA} 1 \mathrm{C}$ and $\mathrm{BP}$, were measured at enrollment. The serum LDL-C level was calculated using the Friedewald equation, except in the case of a TG level higher than $400 \mathrm{mg} / \mathrm{dl}$, in which case the LDL-C data were recorded as 'missing.' Information about previous history of IHD and stroke and findings from a 12-lead ECG were obtained for all patients to assess cardiovascular disease at baseline. The study was approved by the institutional review boards and by the safety monitoring board every year. The organizing committee confirmed all cardiovascular events annually. The guidelines of the Japan Atherosclerosis Society (2002) state that the LDL-C level should be less than $120 \mathrm{mg} / \mathrm{dl}$ and that the HDL-C level should be higher than $40 \mathrm{mg} /$ $\mathrm{dl}$ in diabetic individuals; these clinical guidelines were likely followed by the physicians who were treating these patients at the time of the study [12].

\section{Statistical methods}

The results are presented as the means \pm SD. All statistical analyses were performed using JMP software (SAS Institute, Inc., Cary, NC). The incidences of IHD and CVA were analyzed in relation to the aforementioned risk factors. Cox multivariate regression analyses were used. Because LDL-C/HDL-C interacts strongly with LDL-C and HDL-C and because non-HDL-C interacts with triglyceride and LDL-C, we analyzed non-HDL-C and LDL-C/HDL-C separately. In other words, common factors (gender, age, duration of diabetes, HbA1C, FPG, systolic BP (SBP), and diastolic BP (DBP)),TG, LDL-C and HDL-C were analyzed first. Then, non-HDL-C and common factors were analyzed. Finally, LDL-C/HDL-C, common factors and TG were analyzed. Values of $\mathrm{P}<0.05$ were considered statistically significant.

Definition of major events. Major events such as IHD and CVA were defined as follows.

1. Definite fatal and nonfatal myocardial infarction

( 1 or more of the following criteria must be met):

a) Diagnostic ECG at the time of the event.

b) Ischemic cardiac pain (and/or unexplained acute left ventricular failure) and diagnostic enzyme levels.

c) Ischemic cardiac pain and/or unexplained acute left ventricular failure with both equivocal enzyme levels and equivocal ECG.

d)Diagnostic enzyme levels and equivocal ECG.

e) Angiographic evidence of major artery occlusion with appropriate ventriculographic wall motion 
abnormality where a previous angiogram showed no such abnormality.

f) Postmortem examination.

2. Angina pectoris (stable or unstable, both of the following criteria must be met):

a) Ischemic cardiac pain relieved by nitrates.

b) Equivocal ECG.

3. Ischemic stroke ( 1 of the following conditions must be met):

a) Rapid onset of focal neurologic deficit lasting at least $24 \mathrm{~h}$ or leading to death, plus evidence from neuroimaging (computed tomography or magnetic resonance imaging) showing cerebral/cerebellar infarction or no abnormality, or postmortem examination showing cerebral and/or cerebellar infarction.

b) Rapid onset of global neurological deficit (e.g., coma) lasting at least $24 \mathrm{~h}$ or leading to death, plus evidence from neuroimaging showing infarction, or postmortem examination showing infarction.

c) Focal neurological deficit (mode of onset uncertain) lasting at least $24 \mathrm{~h}$ or leading to death, plus evidence from neuroimaging showing infarction, or postmortem examination showing infarction.

4 Primary intracerebral hemorrhage (1 of the following conditions must be met):

a) Rapid onset of focal neurological deficit lasting at least $24 \mathrm{~h}$ or leading to death, plus neuroimaging or postmortem examination showing primary intracerebral and/or cerebellar hemorrhage.

b) Rapid onset of global neurologic deficit (e.g., coma) lasting at least $24 \mathrm{~h}$ or leading to death, plus evidence from neuroimaging or postmortem examination showing primary intracerebral and cerebellar hemorrhage.

c) Focal neurologic deficit (mode of onset uncertain) lasting at least $24 \mathrm{~h}$ or leading to death, plus evidence from neuroimaging or postmortem examination showing primary intracerebral and/or cerebellar hemorrhage.

In this study, intracerebral hemorrhage was not included in the variable CVA (stroke) because its pathophysiology is reported to be different from other atherosclerotic diseases, such as stroke and ischemic heart disease.

\section{Results}

\section{Subject characteristics}

Table 1 presents the following subject characteristics: plasma lipid levels, including LDL-C, TG, and HDL-C; other relevant metabolic measures, such as HbA1C level, FPG level, and SBP and DBP; the duration of diabetes; and the number of patients who were prescribed medications for hypertension, dyslipidemia, and diabetes, as well as the type, upon enrollment. The levels of HbA1C and HDL-C were not different by age group. Dyslipidemia was observed in $79.1 \%$ of patients, and anti-hyperlipidemic drugs were prescribed for $57.3 \%$ of the total population, of which $83 \%$ were HMG-CoA reductase inhibitors (statins). Statins and insulin were prescribed with the same frequency for late elderly patients as for non-elderly patients. Insulin and oral agents for diabetes treatment were prescribed for $23.9 \%$ and $70.5 \%$ of the late elderly and non-elderly individuals, respectively. Agents for hypertension and diabetes were prescribed more often in late elderly patients than in non-elderly patients. There were also significant differences in several other factors among the age groups.

\section{IHD and CVA incidence}

One hundred fifty-three cases of IHD and 104 CVAs occurred during the 5.5 years of the study, which represented incidences of 7.9 and 5.6 per 1,000 patients per year, respectively. The number of deaths was $59(3.1 / 1,000$ patient-years) over the 5.5 years (Table 2, Figure 1).

The relationships between IHD or CVA and the background factors, such as LDL-C level, in each age group were analyzed by Cox proportional regression analyses (Table 2, Figure 2).

As described in the methods, non-HDL-C and LDL-C/ HDL-C were analyzed separately from other lipids, such as LDL-C and triglyceride or HDL-C. However, significant factors were the same in total and in each generation group, although the $\mathrm{HR}$ and $\mathrm{CI}$ of common factors (gender, age, duration of diabetes, HbA1C, FPG, systolic $\mathrm{BP}(\mathrm{SBP})$, and diastolic BP (DBP)) were slightly different in each (data not shown for the HR and CI of common factors in the analyses of non-HDL-C and LDL-C/HDL-C).

In the total patient population, the levels of $\mathrm{HbA1C}$, LDL-C, and HDL-C, and the LDL-C/HDL-C ratio were significantly related to IHD, and only the HDL-C level was significantly related to a CVA. The HbA1C level, SBP, and LDL-C levels were significantly correlated with IHD in patients less than 65 years old, while the variables female gender, short duration of diabetes and HDL-C level were correlated with IHD in patients older than 75. Because the non-HDL-C level and the LDL-C/ HDL-C ratio have been proposed as markers representing all types of lipids, we included them in a separate model (excluding LDL-C, triglyceride and HDL-C levels 
Table 1 Basic patient profile

\begin{tabular}{|c|c|c|c|c|c|c|c|c|c|c|c|c|c|c|}
\hline \multirow[t]{3}{*}{$n=4014$} & \multirow{2}{*}{\multicolumn{2}{|c|}{$\frac{\text { Total }}{n=4014}$}} & \multirow{2}{*}{\multicolumn{2}{|c|}{$\begin{array}{l}<65 \text { years } \\
n=1267\end{array}$}} & \multirow{2}{*}{\multicolumn{2}{|c|}{$\frac{65-74 \text { years }}{n=1731}$}} & \multirow{2}{*}{\multicolumn{2}{|c|}{$\begin{array}{l}\geq 75 \text { years } \\
n=1016\end{array}$}} & \multirow[t]{3}{*}{ P1 } & \multirow{2}{*}{\multicolumn{2}{|c|}{$\frac{\text { Male }}{n=2078}$}} & \multirow{2}{*}{\multicolumn{2}{|c|}{$\frac{\text { Female }}{n=1936}$}} & \multirow[t]{3}{*}{ P2 } \\
\hline & & & & & & & & & & & & & & \\
\hline & Mean & SD & Mean & SD & Mean & SD & Mean & SD & & Mean & SD & Mean & SD & \\
\hline Gender (\% male) & 51.2 & 53.1 & 49.8 & 49.9 & * & 100.0 & 0 & - & & & & & & \\
\hline Age (yrs,mean/median) & $67.9 / 70$ & 2.0 & $56.5 / 58$ & 7.0 & $70.0 / 70$ & 2.7 & $78.8 / 78$ & 3.5 & - & $67.0 / 69$ & 10.0 & $69.7 / 70$ & 8.7 & $* *$ \\
\hline Duration of DM (months) & 177.9 & 70.0 & 156.3 & 64.5 & 186.1 & 101.2 & 190.7 & 104.3 & $* * *$ & 191.6 & 108.9 & 169.8 & 79.7 & $* *$ \\
\hline $\mathrm{HbA1C}(\%)$ & 7.70 & 0.80 & 7.74 & 1.38 & 7.72 & 1.18 & 7.62 & 1.14 & 0.17 & 7.61 & 1.25 & 7.79 & 1.20 & $* *$ \\
\hline FPG (mg/dl) & 149.8 & 30.3 & 157.9 & 53.2 & 146.4 & 45.7 & 145.4 & 42.0 & $* *$ & 150.9 & 48.8 & 146.9 & 44.9 & 0.17 \\
\hline $\mathrm{SBP}(\mathrm{mmHg})$ & 137.3 & 11.7 & 133.1 & 17.3 & 135.3 & 16.8 & 146.0 & 17.5 & $* *$ & 133.8 & 17.2 & 135.9 & 17.1 & * \\
\hline $\mathrm{DBP}(\mathrm{mmHg})$ & 74.0 & 7.3 & 76.1 & 11.8 & 73.5 & 10.6 & 72.3 & 10.7 & $* * *$ & 74.5 & 11.1 & 73.3 & 10.9 & * \\
\hline TG (mg/dl) & 138.2 & 53.8 & 159.4 & 156.3 & 128.5 & 82.0 & 128.4 & 73.0 & $* * *$ & 142.9 & 126.3 & 131.3 & 83.7 & 0.18 \\
\hline LDL-C (mg/dl) & 118.2 & 21.3 & 121.6 & 33.8 & 117.6 & 32.1 & 115.0 & 29.3 & $*$ & 115.0 & 31.8 & 121.2 & 31.4 & $* *$ \\
\hline HDL-C (mg/dl) & 55.8 & 10.7 & 54.8 & 15.6 & 55.4 & 15.5 & 57.7 & 15.8 & 0.38 & 53.42 & 15.4 & 56.78 & 15.7 & $* *$ \\
\hline Non-HDL-C (mg/dl) & 145.8 & 23.4 & 153.2 & 40.3 & 143.3 & 35.5 & 141.0 & 31.8 & * & 143.6 & 36.9 & 147.5 & 35.6 & * \\
\hline LDL-C/HDL-C & 2.31 & 0.74 & 2.41 & 1.17 & 2.31 & 1.21 & 2.27 & 0.88 & * & 2.33 & 0.95 & 2.33 & 1.28 & 0.21 \\
\hline Agents for HT (\%) & 55.5 & & 49.3 & & 56.0 & & 62.3 & & $* *$ & 48.5 & & 62.0 & & $* * *$ \\
\hline ACEI/ARB & 39.7 & & 36.9 & & 40.4 & & 41.9 & & 0.65 & 35.8 & & 43.4 & & * \\
\hline CCB & 41.2 & & 32.4 & & 43.7 & & 52.6 & & 0.31 & 36.0 & & 46.5 & & * \\
\hline Others & 28.3 & & 22.5 & & 31.8 & & 31.4 & & 0.69 & 28.9 & & 26.7 & & 0.66 \\
\hline Agents for DL (\%) & 57.3 & & 63.8 & & 54.8 & & 52.6 & & $* *$ & 52.1 & & 60.1 & & $* * *$ \\
\hline Strong statins & 29.6 & & 31.1 & & 28.3 & & 25.4 & & 0.36 & 29.7 & & 29.5 & & 0.89 \\
\hline Classical statins & 53.3 & & 47.0 & & 58.0 & & 61.6 & & 0.11 & 51.9 & & 55.0 & & 0.23 \\
\hline Fibrates & 8.9 & & 12.0 & & 6.5 & & 6.8 & & 0.13 & 9.8 & & 7.9 & & 0.18 \\
\hline Others & 8.2 & & 9.9 & & 7.2 & & 6.2 & & 0.10 & 8.6 & & 7.6 & & 0.22 \\
\hline Agents for DM (\%) & 86.6 & & 76.9 & & 91.6 & & 90.3 & & $* *$ & 85.1 & & 88.6 & & * \\
\hline Insulin & 23.9 & & 24.4 & & 24.6 & & 21.7 & & 0.42 & 28.0 & & 32.4 & & * \\
\hline Sulfonylurea & 49.5 & & 41.5 & & 51.3 & & 53.7 & & 0.21 & 50.0 & & 48.9 & & 0.29 \\
\hline Others & 26.1 & & 34.6 & & 21.4 & & 24.5 & & 0.19 & 26.0 & & 22.0 & & * \\
\hline IHD (/1000 year) & 9.68 & & 8.84 & & 10.04 & & 9.87 & & 0.97 & 10.26 & & 9.47 & & 0.32 \\
\hline CVA (/1000 year) & 6.78 & & 4.45 & & 7.44 & & 7.56 & & 0.21 & 7.02 & & 5.72 & & 0.27 \\
\hline
\end{tabular}

P1: Differences in each factor among ages. P2: Differences in each factor between genders. HbA1C:NGSP, ${ }^{* P}<0.05, * * P<0.01,{ }^{* * * P}<0.001$.

to avoid the interactive effect on non-HDL-C, or excluding LDL-C and HDL-C levels for the LDL-C/HDL-C ratio). The non-HDL-C level was only correlated with IHD in patients younger than 65. The LDL-C/HDL-C ratio was significantly correlated with IHD in patients of all generations. Age and lower HDL levels were correlated with CVA in patients over 75 years old (Table 2, Figure 2). Subsequently, we evaluated the relationships with IHD and CVA according to the quartile categories for each age group by Kaplan-Meier estimator curves. The HDL-C level was inversely correlated with IHD and CVA, particularly in individuals over 75 (Figure 3). The LDL-C/HDL-C ratio tended to correlate with IHD in all individuals (Figure 3 ). For the variable current smokers, $6.8 \%$ of the total population of subjects smoked. By age category, 9.9, 6.7 and $3.8 \%$ of patients younger than 65 , patients between 65 and 74, and patients older than 75 smoked, respectively. As the duration of diabetes is pretty long, number of present smokers is not many.

\section{Discussion}

Background and discussion points of the study

The numbers of diabetic elderly and their associated net medical costs have drastically increased in recent decades. The mean life expectancy is now approximately an additional 12 and 16 years at age 75 for males and females in Japan, respectively, although the average life span is 78.9 and 85.6 years, respectively. Consequently, the number of late elderly (individuals older than 75) exceeds 13 million, or $10 \%$ of the total Japanese population. Diabetes can either develop in the elderly or continue through old age after an earlier onset, and the numbers of diabetic elderly are increasing. In Japan, $55 \%$ of diabetic individuals were elderly in 2007, and 
Table 2 Risk factors for IHD and CVA by Cox multivariate models in each age group (IHD, upper; CVA, lower)

\begin{tabular}{|c|c|c|c|c|c|c|c|c|c|c|c|c|}
\hline \multirow{2}{*}{$\frac{n=4014}{\text { IHD }}$} & \multicolumn{3}{|c|}{ Total $(n=4014)$} & \multicolumn{3}{|c|}{$<65$ years $(n=1267)$} & \multicolumn{3}{|c|}{$65-74$ years $(n=1731)$} & \multicolumn{3}{|c|}{$\geq 75$ years $(n=1016)$} \\
\hline & Adjusted HR & $95 \% \mathrm{Cl}$ & $\mathbf{P}$ & Adjusted HR & $95 \% \mathrm{Cl}$ & $\mathbf{P}$ & Adjusted HR & $95 \% \mathrm{Cl}$ & $\mathbf{P}$ & Adjusted HR & $95 \% \mathrm{Cl}$ & $\mathbf{P}$ \\
\hline Gender (women vs. men) & 1.103 & $0.972-1.268$ & 0.197 & 1.044 & $0.967-1.073$ & 0.456 & 1.085 & $0.978-1.210$ & 0.101 & 1.132 & $0.992-1.278$ & $0.019^{*}$ \\
\hline Age (per 10 years) & 1.013 & $0.972-1.066$ & 0.328 & 1.022 & $0.977-1.079$ & 0.229 & 1.054 & $1.002-1.106$ & $0.049^{*}$ & 1.005 & $0.871-1.139$ & 0.682 \\
\hline Duration of Diabetes (months) & 0.995 & $0.988-1.003$ & 0.053 & 1.001 & $0.991-1.008$ & 0.582 & 0.993 & $0.985-0.999$ & $0.033^{*}$ & 0.992 & $0.982-0.999$ & $0.023^{*}$ \\
\hline HbA1C (per 1\%) & 1.171 & $1.001-1.356$ & $0.047^{*}$ & 1.327 & $1.025-1.686$ & $0.032^{*}$ & 1.219 & $0.973-1.487$ & 0.083 & 0.792 & $0.479-1.059$ & 0.134 \\
\hline FPG (per 10 mg/dl) & 1.004 & $0.997-1.008$ & 0.432 & 1.005 & $0.996-1.013$ & 0.355 & 1.004 & $0.997-1.009$ & 0.592 & 0.999 & $0.987-1.007$ & 0.761 \\
\hline SBP(per $10 \mathrm{mmHg}$ ) & 1.008 & $0.995-1.021$ & 0.186 & 1.030 & $1.000-1.055$ & $0.035^{*}$ & 1.014 & $0.994-1.037$ & 0.175 & 0.986 & $0.954-1.014$ & 0.331 \\
\hline DBP(per $10 \mathrm{mmHg}$ ) & 0.995 & $0.978-1.015$ & 0.618 & 0.982 & $0.948-1.024$ & 0.386 & 0.980 & $0.950-1.011$ & 0.206 & 1.027 & $0.986-1.073$ & 0.202 \\
\hline TG (quartile) & 1.005 & $0.889-1.166$ & 0.555 & 1.002 & $0.996-1.006$ & 0.502 & 1.108 & $0.997-1.220$ & 0.065 & 1.001 & $0.961-1.046$ & 0.454 \\
\hline LDL-C (quartile) & 1.318 & $1.103-1.585$ & $0.023^{*}$ & 1.571 & $1.128-2.524$ & $0.016^{*}$ & 1.050 & $0.932-1.176$ & 0.112 & 1.156 & $0.998-1.309$ & 0.054 \\
\hline HDL-C (quartile) & 0.751 & $0.611-0.917$ & $0.005^{* *}$ & 0.828 & $0.646-1.017$ & 0.072 & 0.987 & $0.966-1.008$ & 0.204 & 0.629 & $0.401-0.856$ & $0.001^{* *}$ \\
\hline Non-HDL-C (quartile) & 1.023 & $0.981-1.072$ & 0.075 & 1.025 & $1.001-1.121$ & $0.044^{*}$ & 1.073 & $0.982-1.161$ & 0.086 & 0.941 & $0.791-1.102$ & 0.621 \\
\hline LDL-C/HDL-C (quartile) & 1.583 & $1.298-1.945$ & $0.001^{* *}$ & 2.324 & $1.516-3.795$ & $0.001^{* *}$ & 1.359 & $1.028-1.824$ & $0.021^{*}$ & 1.407 & $1.015-2.592$ & $0.029^{*}$ \\
\hline CVA & Adjusted HR & $95 \% \mathrm{Cl}$ & $\mathbf{P}$ & Adjusted HR & $95 \% \mathrm{Cl}$ & $\mathbf{P}$ & Adjusted HR & $95 \% \mathrm{Cl}$ & $P$ & Adjusted HR & $95 \% \mathrm{Cl}$ & $\mathbf{P}$ \\
\hline Gender & 1.164 & $0.985-1.296$ & 0.351 & 1.014 & $0.897-1.240$ & 0.655 & 1.208 & $0.896-1.526$ & 0.112 & 0.953 & $0.912-1.012$ & 0.063 \\
\hline Age & 1.015 & $0.986-1.039$ & 0.282 & 1.002 & $0.957-1.076$ & 0.754 & 1.007 & $0.916-1.166$ & 0.537 & 1.103 & $1.002-1.217$ & $0.048^{*}$ \\
\hline Duration of Diabetes & 0.998 & $0.992-1.001$ & 0.206 & 1.003 & $0.987-1.017$ & 0.709 & 0.996 & $0.989-1.001$ & 0.096 & 0.999 & $0.991-1.005$ & 0.818 \\
\hline $\mathrm{HbA} 1 \mathrm{C}$ & 1.001 & $0.790-1.214$ & 0.128 & 1.019 & $0.691-1.401$ & 0.814 & 0.997 & $0.855-1.222$ & 0.569 & 0.928 & $0.822-1.010$ & 0.059 \\
\hline$\overline{F P G}$ & 1.005 & $0.995-1.005$ & 0.803 & 1.003 & $0.990-1.018$ & 0.741 & 1.002 & $0.995-1.008$ & 0.592 & 0.998 & $0.986-1.008$ & 0.711 \\
\hline SBP & 1.009 & $0.993-1.024$ & 0.276 & 1.024 & $0.988-1.055$ & 0.185 & 1.015 & $0.992-1.037$ & 0.206 & 0.989 & $0.957-1.018$ & 0.458 \\
\hline$\overline{\mathrm{DBP}}$ & 0.998 & $0.978-1.020$ & 0.846 & 0.995 & $0.958-1.046$ & 0.831 & 0.981 & $0.948-1.016$ & 0.278 & 1.024 & $0.978-1.074$ & 0.317 \\
\hline TG & 1.132 & $0.908-1.302$ & 0.156 & 1.053 & $0.658-1.742$ & 0.833 & 1.253 & $0.900-1.780$ & 0.184 & 1.169 & $0.746-1.853$ & 0.497 \\
\hline LDL-C & 1.009 & $0.912-1.191$ & 0.675 & 1.005 & $1.001-1.100$ & $0.047^{*}$ & 1.015 & $0.892-1.136$ & 0.714 & 0.997 & $0.982-1.012$ & 0.631 \\
\hline HDL-C & 0.742 & $0.596-0.901$ & $0.003^{* *}$ & 0.715 & $0.591-1.191$ & 0.200 & 0.750 & $0.494-1.000$ & $0.049^{*}$ & 0.536 & $0.320-0.851$ & $0.007^{* *}$ \\
\hline Non-HDL-C & 0.981 & $0.945-1.019$ & 0.206 & 1.021 & $1.003-1.141$ & $0.045^{*}$ & 0.942 & $0.872-1.013$ & 0.172 & 1.012 & $0.954-1.077$ & 0.226 \\
\hline LDL-C/HDL-C & 1.180 & $0.951-1.477$ & 0.132 & 1.271 & $0.819-2.232$ & 0.263 & 1.114 & $0.853-1.582$ & 0.356 & 1.209 & $0.803-1.847$ & 0.364 \\
\hline
\end{tabular}

The top panels show the analyses of IHD for subjects aged $<65$ years (left), $65-74$ years (middle) and $\geq 75$ years (right). The lower panels show the incidence of CVA. Bold indicate statistically significant factors. Hazard ratios and $95 \%$ Cls are shown. The ratio of males to females was 1 . As LDL-C/HDL-C interacts strongly with LDL-C and HDL-C, and non-HDL-C interacts triglyceride and LDL-C, analysis of

non-HDL-C and LDL-C/HDL-C were separately shown in methods section. 


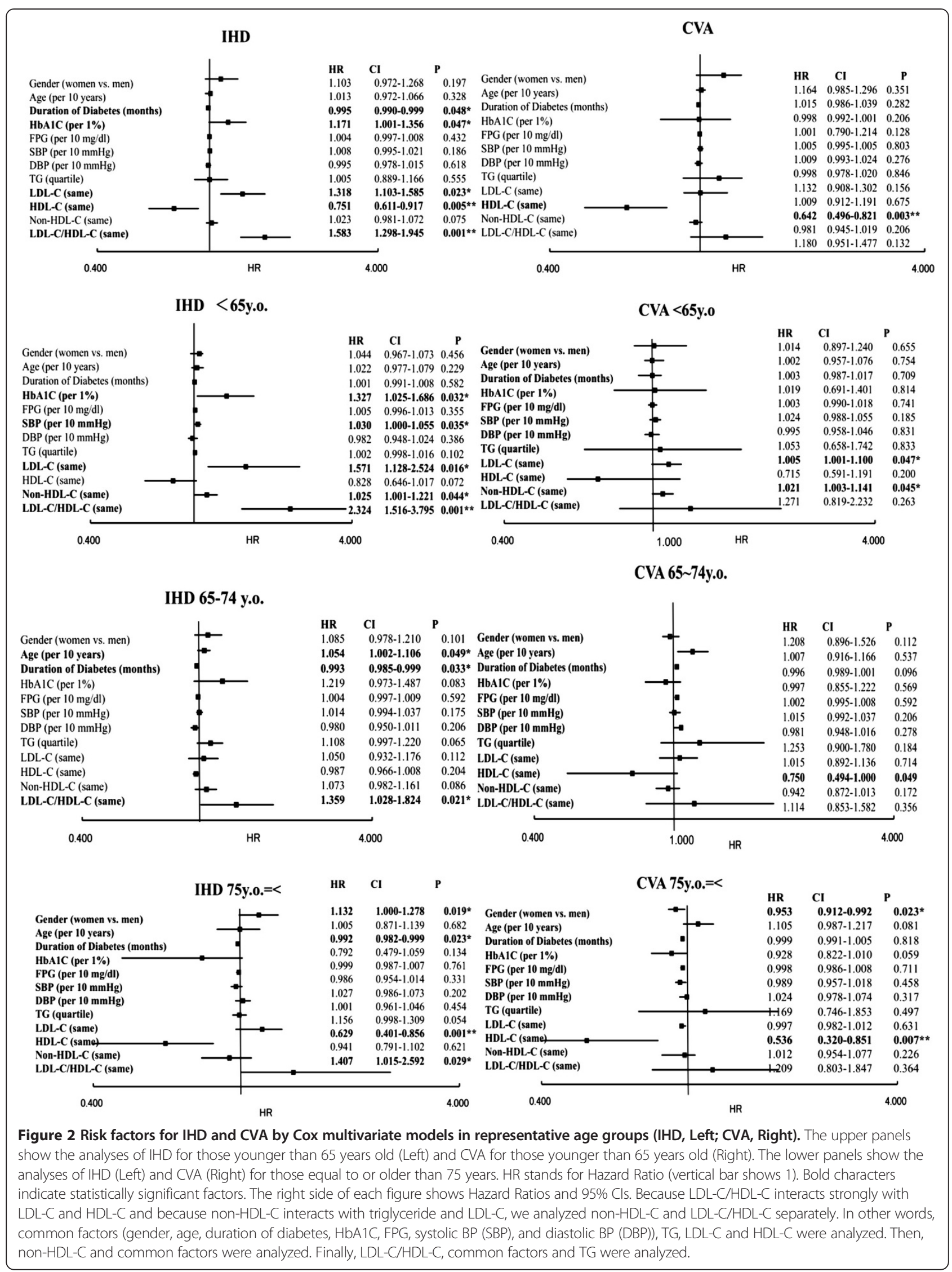



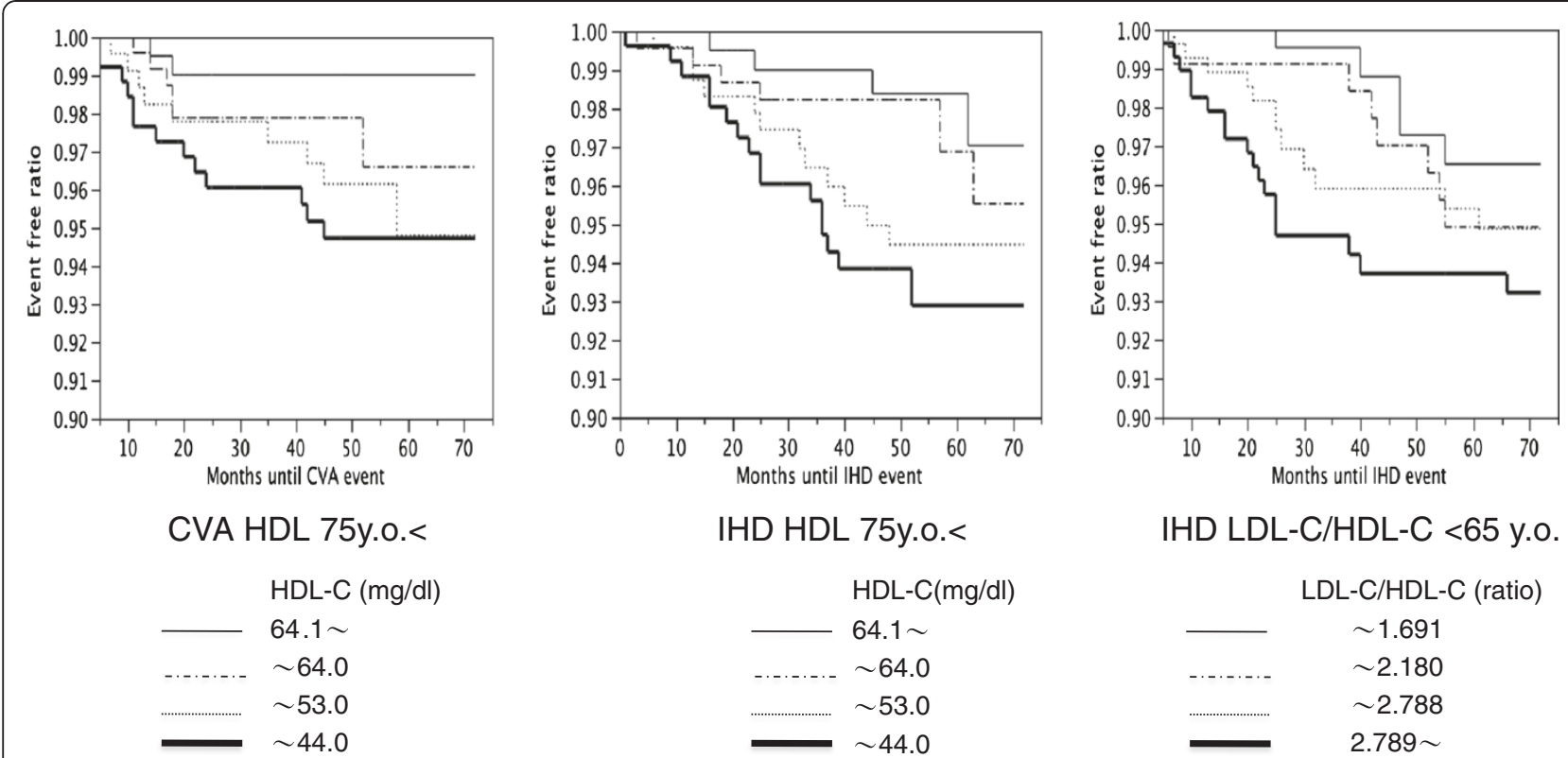

Figure 3 The relationships of HDL-C levels and the LDL-C/HDL-C ratio with IHD and CVA in quartile categories for each age group based on Kaplan-Meier estimator curves. Left: The LDL-C/HDL-C ratio correlates with IHD. The figure shows the data for individuals aged $<65$ years. Center: The HDL-C level was inversely correlated with HHD, particularly in individuals aged $>75$ years. Right: The association between CVA and HDL-C was more prominent in those individuals aged $\geq 75$ years. Quartile categories HDL-C: $-<44.0, \cdots \cdots$

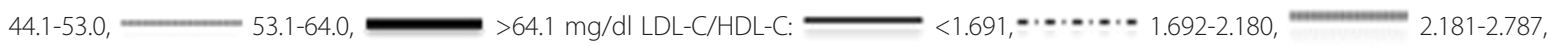
$>2.789$.

approximately $25 \%$ were late elderly. These trends are spreading across the world, mainly in developed countries; however, the risk factors for IHD or CVA in late elderly diabetic individuals have not been identified. In the late elderly, atherosclerotic diseases, such as IHD and CVA, are a more frequent cause of death than malignancy. In Canada, diabetic patients are reported to suffer myocardial infarction approximately 14 years earlier than patients without diabetes [13]. However, there is little evidence on the risk and preventive factors for IHD or CVA in the diabetic elderly, and there are no reports on the late elderly $[14,15]$.

Therefore, we organized this study as one of the largest attempts to examine IHD and CVA in middle-aged to elderly diabetic individuals. We defined the age categories as follows: 1) non-elderly: younger than 65,2 ) early elderly: from 65 to 74, and 3) late elderly: equal to or older than 75. Sixty-five is usually defined as the threshold for being elderly worldwide $[13,16]$, and 75 is the beginning of the late elderly age in Japan, as defined by health insurance and care insurance systems and the Japan Geriatric Society [12].

\section{The effect of age on IHD and CVA risk factors}

One hundred fifty-three cases of IHD and 104 CVAs occurred, which represents 7.8 and $5.7 / 1,000$ people per year, respectively, over this 5.5-year study, although we defined stroke strictly and excluded cerebral and subarachnoid hemorrhages from this definition. IHD occurs 2 to 3 times more frequently in diabetic individuals compared to the normal Japanese population, and CVA also occurs more frequently in diabetic individuals [17]. The prevalence of IHD and CVA is slightly higher than reported in previous Japanese diabetic studies because we targeted relatively older diabetic individuals $[16,17]$. However, even in diabetic individuals, the combined frequency of IHD and stroke was slightly lower in the Japanese population than among Caucasians [18].

To look for the candidate metabolic markers that may predict IHD and CVA in various age groups, Cox regression analyses were performed. The analyses showed that higher $\mathrm{HbA} 1 \mathrm{C}$ and LDL-C levels, SBP and non-HDL-C were significantly correlated with the occurrence of IHD in subjects $<65$ years old, which is similar to previous reports [14-16]. The ratio of males/females was not significantly different between patients $<65$, patients between 65 and 74, and patients $\geq 75$. A relation between diabetes and ischemic stroke was reported. Patients (59.8 \pm 7.2 y.o.) having a history of coronary heart disease with diabetes mellitus exhibited a 2.29-fold increased risk for stroke or TIA during the 4.8- to 8.1-year follow-up period than patients without diabetes. Impaired fasting 
glucose and hypertension were predictors, while HDL-C was not. These results are fairly consistent with those of the younger patients group ( $<65$ y.o. $)$ in the present study [19].

In patients $\geq 75$ y.o., a lower HDL-C level was correlated with IHD and CVA. This is a novel finding of the present study. Few data are available on the relationship between elderly type 2 diabetic patients and CVA, particularly among the late elderly [16-18,20]; therefore, the finding of the importance of HDL-C in CVA in the late diabetic elderly may be important. The Kaplan-Meier estimator curves, which are shown in Figure 1, support these findings.

Thus, a lower HDL-C level is an important risk factor for both IHD and CVA among the late elderly diabetic patients in this study. Although the protective effects of higher HDL-C on IHD in the non-elderly are known, the effects on IHD among late elderly diabetics are not known [21]. The CVA and IHD incidences in the late elderly may decrease to the levels found in middle-aged cohorts if higher HDL-C has protective effects on late elderly diabetic individuals and if their levels are easily increased. There are few agents available to increase HDL-C levels, except exercise, and adequate exercise or bodily movement may be necessary even in the elderly. The low HDL-C level may be related to low levels of physical activity in the elderly, which could influence a CVA in many ways that are separate from the HDL-C level. Atherosclerosis is an inflammatory disorder, and HDL-C may preserve endothelial function by increasing endothelial NO [22].

For LDL-C, three large-scale clinical studies on dyslipidemia, which included participants who were up to 75 or 80 years of age, are available [23-25]. Although these studies reported that the reduction in LDL-C by statins decreases IHD (including in diabetic people), the effects were weak in the elderly compared with those in the non-elderly (e.g., Prosper reported that pravastatin, a water-soluble statin, induced a $16 \%$ decrease in IHD without any effect on CVA in elderly patients compared to a $21 \%$ decrease in non-elderly patients). These data suggest that simply controlling LDL-C may not prevent IHD or CVA in the elderly. There are also no large observational studies on the diabetic elderly older than 75 $[26,27]$. For example, the international FIELD study analyzed approximately 10,000 patients up to the age of 75 years, with a mean age 63 years [26], and the Swedish NDR-study analyzed 18,673 patients up to 70 years old, with a mean age of 60 years [27]. These large observational studies, analyzing all patients, found LDL-C, nonHDL-C, HDL-C, triglycerides and ratios of LDL-C/ HDL-C and total-cholesterol/HDL-C to be significant risk factors for IHD. These data are consistent with our data on participants younger than 65 , although those observational studies did not include patients older than 75. To lower LDL-C levels, $57 \%$ of the patients in our study had already been prescribed anti-dyslipidemic agents, of which $83 \%$ were statins. The average LDL-C level was $120 \mathrm{mg} / \mathrm{dl}$, which matches the guidelines of the Japan atherosclerosis society but not that of the American Heart Association or IDF $(100 \mathrm{mg} / \mathrm{dl})$. Although doses and types of anti-dyslipidemic agents were changed often during the study, their effects other than LDL reduction (pleiotropic effects) cannot be evaluated yet.

Our study shows the importance of the LDL-C/HDL-C ratio as well as HDL-C and LDL-C levels, although the strength of these effects is different based on age. The LDL-C/HDL-C ratio was associated with IHD, which may represent the effect of LDL-C levels in the non-elderly and HDL-C levels in the elderly [28]. The non-HDL-C level and the total cholesterol/HDL-C ratio are also proposed markers of atherosclerotic diseases [29,30]. The non-HDL-C level was associated with IHD only among those younger than 65 , and the total cholesterol/HDL-C ratio was not significantly associated with IHD (data not shown). We believe that these data are consistent with previous data from non-elderly diabetic individuals because the non-HDL-C level is a reflection of the effect of triglyceride levels, and hyper-triglyceridemia, complicated with metabolic syndrome, occurs more often in nonelderly than in elderly people.

Emerging Risk Factors Collaboration analysis showed the association of non-HDL-C with IHD and CVA. However, in this study, it was associated with CVA only in those younger than 65 . The two studies are different in that 1) our cohort consisted only of diabetic patients; 2) in the Collaboration analysis, the mean age was 56.6 y.o., compared to 67.4 y.o. in our study; and 3) in the Collaboration analysis, almost all of the patients were North American or European, whereas our study was Japanese patients only. In the elderly, triglycerides are usually lower than in younger individuals, and nonHDL-C represents triglyceride.

A 1-mg/dl change in HDL-C and/or a 2-mg/dl change in LDL-C reflect a $2 \%$ change in the risk for atherosclerotic diseases, and this may be partially consistent within our diabetic elderly study [31]. The LDL-C/HDL-C ratio may reflect the direct effects of both LDL-C and HDL-C levels, which may affect or interact with the progression of atherosclerosis and thrombosis formation more than other lipids, such as chylomicrons and chylomicron remnants, which are represented by the non-HDL-C level or the TC/HDL-C ratio. The fact that elderly individuals have different risk factors than younger individuals could be associated with genetic protection from such events or an accumulation of personal habits that may provide the elderly with protection. For example, differences in single nucleotide polymorphisms (SNP) 
may be related to the severity of atherosclerosis and, subsequently, to the different effects of predictors by age and should be evaluated in the future [32].

Interestingly, impaired fasting glucose and hypertension were the strongest predictors of risk for ischemic stroke or TIA in metabolic syndrome, and $\mathrm{HbA1c}$ had positive associations with glycemia, TG, HDL-C, and TG/HDL-C but not LDL-C in the study of 118 older adults aged $65-95$ years, of whom less than $6.5 \%$ had an HbA1c of $93 \%[19,33]$. These data is consistent with our data in diabetic patients younger than 65 [33]. Another study evaluated the predictors of stroke stratified by age (at symptom onset: young; <50 years, older; $51-75$ years, and oldest; $75<$ years) using data collected over a 4 -year period from 3,053 subjects with stroke. The metabolic syndrome was the only predictor among the older patients (OR 1.58) but not in the others. Although most patients were not diabetic, these types of studies should be accumulated to evaluate the effect of age on atherosclerotic diseases [34].

\section{Conclusions}

HbA1C, LDL-C, SBP and non-HDL-C in non-elderly diabetic individuals, HDL-C in late elderly diabetic individuals and the $\mathrm{LDL}-\mathrm{C} / \mathrm{HDL}-\mathrm{C}$ ratio in all diabetic individuals were associated with IHD in this population. HDL-C was also associated with CVA in late elderly diabetic individuals. The differences in atherosclerotic risk by age must be considered in developing individualized strategies for the prevention of atherosclerotic diseases. Because this was an observational study, we could not analyze the detailed effects of treatment, such as the effect of statins on the risk of IHD or CVA. Although this study targets Japanese, these new findings on metabolic markers in the late elderly could provide additional data for the annotation of cardiovascular risk factors in the diabetic elderly across the world.

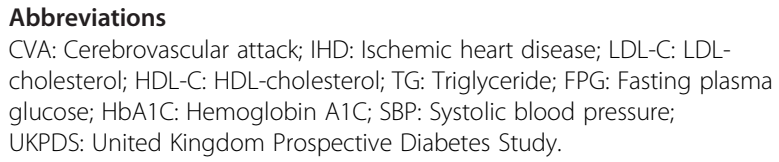

Abbreviations

CVA: Cerebrovascular attack; IHD: Ischemic heart disease; LDL-C: LDLcholesterol; HDL-C: HDL-cholesterol; TG: Triglyceride; FPG: Fasting plasma glucose; HbA1C: Hemoglobin A1C; SBP: Systolic blood pressure; UKPDS: United Kingdom Prospective Diabetes Study.

All authors take responsibility for all aspects of the reliability and freedom from bias of the data presented and their discussed interpretation.

\section{Competing interests}

The authors declare that they have no competing interests.

\section{Authors' contributions}

$\mathrm{TH}$ and HN wrote the manuscript and researched the data. AA, SK, HS, HW, $\mathrm{TO}, \mathrm{KY}, \mathrm{MT}, \mathrm{KK}, \mathrm{MN}, \mathrm{HN}$, and $\mathrm{KI}$ contributed to the research and reviewed the manuscript. All authors read and approved the final manuscript.

\section{Acknowledgments}

We thank the following people for contributing to this research by researching and analyzing the data: I. Sakuma (Kales Sapporo Hospital),
H. linuma and K. Ohashi (Tokyo University), S. Tanaka (Kyoto University), M. Yoshizumi (Hiroshima University), and H. Umegaki (Nagoya University). This work was supported in part by a grant from The Japanese Ministry of Health, Welfare and Labor. The funding body had no role in its design; in the collection, analysis, and interpretation of data; in the writing of the manuscript; or in the decision to submit the manuscript for publication.

\section{Author details}

'Department of Geriatrics, Nagoya University Graduate School of Medicine, 65 Tsuruma-cho, Showa-ku, Nagoya, Japan. ${ }^{2}$ Division of Diabetes, Metabolism and Endocrinology, Tokyo Metropolitan Geriatric Hospital, Tokyo, Japan. ${ }^{3}$ Osaka Saiseikai Nakatsu Hospital, Osaka, Japan. ${ }^{4}$ Department of Internal Medicine, Endocrinology and Metabolism, Niigata Graduate School of Medicine, Niigata, Japan. ${ }^{5}$ Department of Clinical Pharmacology and Therapeutics, Hamamatsu University School of Medicine, Hamamatsu, Japan. ${ }^{6}$ Department of Geriatric Medicine, Tohoku University School of Medicine, Sendai, Japan. ${ }^{7}$ Division of Diabetes, Metabolism and Endocrinology, Department of Internal Medicine, Chiba University Hospital, Chiba, Japan. ${ }^{8}$ Department of Pharmacoepidemiology, Faculty of Medicine, University of Tokyo, Tokyo, Japan. ${ }^{9}$ Department of Diabetes and Metabolic Medicine, National Center for Global Health and Medicine, Tokyo, Japan. ${ }^{10}$ Department of Geriatrics, Nagoya Kita Hospital, Nagoya, Japan.

Received: 10 October 2012 Accepted: 6 January 2013

Published: 9 January 2013

\section{References}

1. Turner RC, Millns H, Neil HA, Stratton IM, Manley SE, Matthews DR, Holman RR: Risk factors for coronary artery disease in non-insulin dependent diabetes mellitus: United Kingdom Prospective Diabetes Study (UKPDS: 23). BMJ 1998, 316:823-828.

2. UK Prospective Diabetes Study (UKPDS) Group: Effect of intensive bloodglucose control with metformin on complications in overweight patients with type 2 diabetes (UKPDS 34). Lancet 1998, 352:854-865.

3. Kahn R, Robertson RM, Smith R, Eddy D: The impact of prevention on reducing the burden of cardiovascular disease. Diabetes Care 2008, 31:1686-1696.

4. Sone H, Yamada N, Mizuno S, Ohashi Y, Ishibashi S, Yamazaki Y: Requirement for hypertension and hyperlipidemia medication in U.S. and Japanese patients with diabetes. Am J Med 2004, 117:711-712.

5. IDF Clinical Guidelines Task Force: Global Guideline for Type 2 Diabetes: recommendations for standard, comprehensive, and minimal care. Diabet Med 2006, 23:579-593.

6. American Diabetes Association Consensus Panel: Guidelines for computer modeling of diabetes and its complications (consensus statement). Diabetes Care 2004, 27:2262-2265.

7. Hata Y, Mabuchi H, Saito Y, Itakura H, Egusa G, Ito H, Teramoto T, Tsushima M, Tada N, Oikawa S, Yamada N, Yamashita S, Sakuma N, Sasaki J, working committee on JAS Guideline for Diagnosis and Treatment of Hyperlipidemias: Report of the Japan Atherosclerosis Society (JAS) guideline for diagnosis and treatment of hyperlipidemia in Japanese adults. J Atheroscler Thromb 2002, 9:1-27.

8. Fruchart JC, Nierman MC, Stroes ES, Kastelein JJ, Duriez P: New risk factors for atherosclerosis and patient risk assessment. Circulation 2004, 109:||115-|19.

9. Danaei G, Finucane MM, Lu Y, Singh GM, Cowan MJ, Paciorek CJ, Lin J, Farzadfar F, Khang YH, Stevens GA, Rao M, Ali MK, Riley LM, Robinson CA, Ezzati M, on behalf of the Global Burden of Metabolic Risk Factors of Chronic Diseases Collaborating Group (Blood Glucose): 2011 National, regional, and global trends in fasting plasma glucose and diabetes prevalence since 1980: systematic analysis of health examination surveys and epidemiological studies with 370 country-years and $2 \cdot 7$ million participants. Lancet 2011, 378:31-40.

10. Neville SE, Boye KS, Montgomery WS, Iwamoto K, Okamura M, Hayes RP: 2009 Diabetes in Japan: a review of disease burden and approaches to treatment. Diabetes Metab Res Rev 2009, 25:705-716.

11. Japanese Research of Cholesterol and Diabetes Mellitus (Japan CDM: UMIN Clinical Trials Registry. 2004 ID of this investigation UMIN000000516 Japan CDM [article online]; 2004. Available from https://upload.umin.ac.jp/ cgi-open-bin/ctr/ctr.cgi?function = brows\&action = brows\&recptno = R000000624\&type $=$ summary\&language $=E$. 
12. Announcement on the current status of Japan's Social Security System from Japan Ministry of Health, Labour and Welfare. 2010, http://www. mhlw.go.jp/english/social_security/kaikaku_1.html.

13. Holman RR, Paul SK, Bethel MA, Matthews DR, Neil HA: 10-year follow-up of intensive glucose control in type 2 diabetes. N Engl J Med 2008, 359:1577-1589.

14. Zhang $P$, Imai $K$ : The relationship between age and healthcare expenditure among persons with diabetes mellitus. Expert Opin Pharmacother 2007, 8:49-57.

15. Hornick T, Aron DC: Preventing and managing diabetic complications in elderly patients. Cleve Clin J Med 2007, 75:153-158.

16. Sone H, Mizuno S, Ohashi Y, Yamada N: Type 2 diabetes prevalence in Asian subjects. Diabetes Care 2004, 27:1251-1252.

17. Doi Y, Ninomiya T, Hata J, Fukuhara M, Yonemoto K, Iwase M, lida M Kiyohara Y: Impact of glucose tolerance status on development of ischemic stroke and coronary heart disease in a general Japanese population: the Hisayama study. Stroke 2010, 41:203-209.

18. Béjot Y, Giroud M: Stroke in diabetic patients. Diabetes Metab. 2010, 36:S84-87.

19. Koren-Morag N, Goldbourt U, Tanne D: Relation between the metabolic syndrome and ischemic stroke or transient ischemic attack: a prospective cohort study in patients with atherosclerotic cardiovascular disease. Stroke. 2005, 36:1366-71.

20. Radermecker RP, Scheen AJ: Management of blood glucose in patients with stroke. Diabetes Metab 2010, 36:S94-99.

21. Windler E, Schöffauer M, Zyriax BC: The significance of low HDLcholesterol levels in an ageing society at increased risk for cardiovascular disease. Diab Vasc Dis Res 2007, 4:136-142.

22. Valensi P, Pariès J, Brulport-Cerisier V, Torremocha F, Sachs RN, Vanzetto G, Cosson E, Lormeau B, Attali JR, Maréchaud R, Estour B, Halimi S: Predictive value of silent myocardial ischemia for cardiac events in diabetic patients: influence of age in a French multicenter study. Diabetes Care 2005, 28:2722-2727.

23. Shepherd J, Blauw GJ, Murphy MB, Bollen EL, Buckley BM, Cobbe SM, Ford I, Gaw A, Hyland M, Jukema JW, Kamper AM, Macfarlane PW, Meinders AE, Norrie J, Packard CJ, Perry IJ, Stott DJ, Sweeney BJ, Twomey C, Westendorp RG, PROSPER study group: Pravastatin in elderly individuals at risk of vascular disease (PROSPER): a randomized controlled trial. Lancet 2002, 360:1623-1630.

24. Heart Protection Study Collaborative Group: 2002 MRC/BHF Heart Protection Study of cholesterol lowering with simvastatin in 20,536 high-risk individuals: a randomized placebo-controlled trial. Lancet 2002, 360:7-22

25. Sever PS, Poulter NR, Dahlöf B, Wedel H, Collins R, Beevers G, Caulfield M Kjeldsen SE, Kristinsson A, Mclnnes GT, Mehlsen J, Nieminen M, O'Brien E, Ostergren J: Reduction in cardiovascular events with atorvastatin in 2,532 patients with type 2 diabetes: Anglo- Scandinavian Cardiac Outcomes Trial-lipid-lowering arm (ASCOT-LLA). Diabetes Care 2005, 28:1151-1157.

26. Davis TM, Ting R, Best JD, Donoghoe MW, Drury PL, Sullivan DR, Jenkins AJ, O'Connell RL, Whiting MJ, Glasziou PP, Simes RJ, Kesäniemi YA, Gebski VJ, Scott RS, Keech AC: 2011 Fenofibrate Intervention and Event Lowering in Diabetes Study investigators. Effects of fenofibrate on renal function in patients with type 2 diabetes mellitus: the Fenofibrate Intervention and Event Lowering in Diabetes (FIELD) Study. Diabetologia 2011, 54:280-290.

27. Gudbjörnsdottir S, Eliasson B, Eeg-Olofsson K, Zethelius B, Cederholm J: National Diabetes Register (NDR). Additive effects of glycaemia and dyslipidaemia on risk of cardiovascular diseases in type 2 diabetes: an observational study from the Swedish National Diabetes Register. Diabetologia 2011, 54:2544-51.

28. Fukuda Y, Miura S, Tsuchiya Y, Inoue-Sumi Y, Kubota K, Takamiya Y, Kuwano T, Ohishi H, Ike A, Mori K, Yanagi D, Nishikawa H, Shirai K, Saku K, Urata H: Lower frequency of non-target lesion intervention in post-successful percutaneous coronary intervention patients with an LDL to HDL cholesterol ratio below 1.5. Int J Cardiol 2011, 149:120-2.

29. DeGoma EM, DeGoma RL, Rader DJ: Beyond high-density lipoprotein cholesterol levels evaluating high-density lipoprotein function as influenced by novel therapeutic approaches. J Am Coll Cardiol 2008, 51:2199-2211.

30. Ramjee $V$, Sperling LS, Jacobson TA: Non-high-density lipoprotein cholesterol versus apolipoprotein B in cardiovascular risk stratification: do the math. J Am Coll Cardiol 2011, 58:457-463.
31. Marshall SM, Flyvbjerg A: Prevention and early detection of vascular complications of diabetes. BMJ 2006, 333:475-480.

32. Funami J, Hayashi T, Nomura H, Ding QF, Ishitsuka-Watanabe A, Matsui-Hirai $\mathrm{H}$, Ina K, Zhang J, Yu ZY, Iquchi A: Clinical factors such as B-type natriuretic peptide link to factor VII, endothelial NO synthase and estrogen receptor alpha polymorphism in elderly women. Life Sci 2009, 85:316-21

33. Martins RA, Jones JG, Cumming SP, Coelho e Silva MJ, Teixeira AM, Veríssimo MT: Glycated hemoglobin and associated risk factors in older adults. Cardiovascular Diabetology 2012, 11:13.

34. Bang OY, Saver JL, Liebeskind DS, Lee PH, Sheen SS, Yoon SR, Yun SW, Kim GM, Chung CS, Lee KH, Ovbiagele B: Age-Distinct Predictors of Symptomatic Cervicocephalic Atherosclerosis. Cerebrovasc Dis 2009, 27:13-21.

doi:10.1186/1475-2840-12-10

Cite this article as: Hayashi et al:: Metabolic predictors of ischemic heart disease and cerebrovascular attack in elderly diabetic individuals: difference in risk by age. Cardiovascular Diabetology 2013 12:10.

\section{Submit your next manuscript to BioMed Central and take full advantage of:}

- Convenient online submission

- Thorough peer review

- No space constraints or color figure charges

- Immediate publication on acceptance

- Inclusion in PubMed, CAS, Scopus and Google Scholar

- Research which is freely available for redistribution 